\title{
Study on the temperature dependence of gas permeation and adsorption behavior of the vacuum insulation panel with getter materials
}

\author{
Hideya Yamamoto $^{1,2^{*}}$ and Daisuke Ogura ${ }^{2}$ \\ ${ }^{1}$ Asahi Fiber Glass Co., Ltd., Technology Development Division, 2530111 Kanagawa, Japan, \\ ${ }^{2}$ Kyoto University, Department of Architecture and Architectural Engineering, 6158540 Kyoto, Japan,
}

\begin{abstract}
Vacuum insulation panel (VIP) is a high-performance heat insulation material that has contributed to the energy efficiency of refrigerators, vending machines, and cooler boxes. Glass wool or fumed silica covered by a laminated film are the core materials of VIP; by evacuating air inside, it is possible to reduce the gas thermal conductivity to be close to 0 and exhibit high thermal performance. In recent years, the research on long-term performance prediction has been conducted for use in building insulation. Specifically, various getter materials have been developed to improve the long-term performance of glass wool VIP. However, there are no studies that clearly show the adsorption behavior or temperature dependence inside VIP with getter materials. We measured the adsorption temperature dependence of two types of getters using the constant volume method and then observed the adsorption behavior inside VIP using VIP equipped with a micro pressure sensor. Regarding the internal pressure of VIPs equipped with the micro pressure sensor, the pressure fluctuation derived from the adsorbent was confirmed by the temperature change, and it was confirmed that the thermal conductivity changed accordingly. If the internal temperature of VIP increases, gases may be released from the getter. Therefore, in the building environment, it is necessary to select a getter that is suitable for the usage environment and to use an appropriate amount of getter.
\end{abstract}

\section{INTRODUCTION}

The insulation performance of porous structures under vacuum conditions has been thoroughly investigated, and its mechanism and physical properties have been clarified [1]. Furthermore, the VIP market has been gradually expanding since 2000 owing to the development of core materials and barrier films. The VIPs core contains either a glass fiber or a fumed silica core. The glass fiber core is used in most VIPs markets in Asia because of its high insulation performance, lower than $10 \mathrm{~Pa}$ internal pressure and low cost. The high insulation performance of glass fiber core VIP shows the potential to reduce the wall thickness and enhance energy savings when VIP are used in building applications.[2-5] However, even though many studies have discussed the long-term performance of VIP in a constant environment, the long-term performance of VIPs has not been measured in a building environment. This lack of actual measurement data indicates that the accuracy of long-term performance predictions in building environments cannot be confirmed. Furthermore, most of the abovementioned studies have focused on fumed silica core VIPs, and only a few studies have investigated glass fiber core VIP [6-9]. Specifically, the long-term performance of glass fiber core VIP cannot be accurately estimated without carefully examining the getter materials required to maintain a constant internal pressure in glass fiber core VIP. In addition, some of the materials used in previous studies have been identified to be a health risk; because they are used in metal containers, there remains a problem in terms of recycling. [9, 10] This report describes the internal gas adsorption behavior of VIP with zeolite, which has been used as a separation membrane, adsorbent, and catalyst. These non-hazardous materials can be easily discarded or recycled and have been confirmed to have high gas adsorption capacity even in vacuum. Regarding the adsorption characteristics of zeolite, the $\mathrm{N}_{2}$ adsorption measurement at $77 \mathrm{~K}$ is performed to measure the pore size. However, for VIP, the adsorption characteristics at room temperature or higher are important; thus, the adsorption characteristics at $283-363 \mathrm{~K}$ were measured using two types of getters.

\section{Aging model}

\subsection{Thermal conductivity at vacuum conditions (with a desiccant) [11]}

Assuming that the initial internal pressure of the VIP is a vacuum unaffected by gas heat transfer, the value of

\footnotetext{
Corresponding author: h-yamamotop@aftgc.co.jp, yamamoto.hideya.65n@.st.kyoto-u.ac.jp,
} 
$\lambda_{\text {cop,ini }}$, the initial insulation performance in the center of the VIP panel, includes the solid and radiative heat transfer of the material. The long-term performance of VIP can be calculated approximately as the change in VIP internal pressure with respect to the time change of gas permeation from the outside and outgas from the material, and can be expressed by equation (1).

$$
\lambda_{\text {cop }}=\lambda_{\text {ini,cop }}+\lambda_{g}
$$

The increase in thermal conductivity due to gas is divided into dry air and water vapor. However, in general, a desiccant is used on the glass fiber core VIP, and the increase in thermal conductivity due to water vapor can be ignored until a desiccant is saturated.

$$
\lambda_{\text {cop }}=\lambda_{\text {ini,cop }}+\lambda_{g a}
$$

Therefore, when dry air is $\lambda_{g a}$, it is expressed as The dependence of thermal conductivity on the gas pressure can be approximated by

$$
\lambda_{g a}=\frac{\lambda_{g a, 0}(T)}{1+\frac{P_{1 / 2, a}}{P a}}
$$

where $P_{1 / 2, a}$ is the pressure at which the thermal conductivity is one-half of $\lambda_{g a, 0}$, and $\lambda_{g a, 0}$ is the thermal conductivity of a still, dry, convection-free air. By combining the solid and radiation conduction in vacuum and Equation (3), which represents gas conduction, the thermal conductivity of VIP can be expressed by Equation (4).

$$
\lambda_{\text {cop }}=\lambda_{\text {cop }, \text { ini }}+\frac{\lambda_{g a, 0}(T)}{1+\frac{P_{1 / 2, a}}{P a}}
$$

\subsection{Permeability of dry air}

On the basis of the mass balance equation for air permeation into VIP and the state equation of an ideal gas $\left(P_{i} V_{\text {eff }}=m_{i} / M_{i} R T\right)$, the change in internal pressure resulting from the permeation of dry air can be expressed as

$$
\begin{aligned}
& \frac{d m_{a}}{d t}=\frac{M_{a} \cdot V_{e f f}}{R \cdot T} \cdot \frac{d P_{a}}{d t}=K_{a, t o t a l} \cdot\left(P_{a, a t m}-P_{a}\right) \\
& P_{a}=P_{a, a t m}-\left(P_{a, a t m}-P_{a(0)}\right) \exp \left(-\frac{K_{a, t o t a l} R T}{M_{a} V_{e f f}} t\right)
\end{aligned}
$$

$K_{a, \text { total }}$ represents the temperature dependence of gas permeation, which is experimentally determined and expressed as an Arrhenius equation. Therefore, if the temperature dependence of the gas permeation of VIP is known, the time change of the internal pressure increase can be obtained from Equation (6).

\subsection{Aging model with a getter}

Glass fiber core VIP absorb the gas flowing from the outside with a getter and can maintain a low internal pressure. When $W_{a d}$, which represents the amount of getter adsorption, is added to Equation (5), Equation (7) is obtained; by replacing $\frac{d W_{a d}}{d P a}$ with $\mathrm{f}(\mathrm{P}, \mathrm{T})$, Eq. (8)

$$
\begin{gathered}
\frac{d m_{a}}{d t}=\frac{M_{a} \cdot V_{e f f}}{R \cdot T} \cdot \frac{d P_{a}}{d t}=K_{a, t o t a l} \cdot\left(P_{a, a t m}-P_{a}\right)+W_{a d} \\
P_{a}=P_{a, a t m}-\left(P_{a, a t m}-P_{a(0)}\right) \exp \left(-\frac{K_{a, t o t a l}}{\frac{M_{a} V_{e f f}}{R T}+f(P, T)} t\right)
\end{gathered}
$$

\subsection{Arrhenius plot}

Assuming that the temperature and pressure of the environmental conditions to be determined are $T_{e x}, \mathrm{P}\left(T_{e x}\right)$, from Equation (5), the gas permeability $K_{a, t o t a l}$ of dry air is determined as follows:

$$
K_{a, \text { total }}=\frac{1}{\left(P_{a, a t m}-p(0)\right)} \quad \frac{M_{a} V_{\text {eff }}}{R T_{e x}} \quad \frac{d P\left(T_{e x}\right)}{d t}
$$

When calculating the time rate of internal pressure from the measurement result of the thermal conductivity, it is necessary to use the average temperature when measuring the thermal conductivity and pressure $\lambda_{c}, P\left(T_{c}\right)$.

$$
\mathrm{P}\left(\mathrm{T}_{\mathrm{ex}}\right)=\frac{\mathrm{P}\left(\mathrm{T}_{\mathrm{c}}\right)}{\mathrm{T}_{\mathrm{c}}} \mathrm{T}_{\mathrm{ex}}
$$

By substituting this Equation into Equation (10),

$$
K_{a, \text { total }}=\frac{1}{\left(P_{a, a t m}-p(0)\right)} \cdot \frac{M_{a} V_{e f f}}{R T_{c}} \cdot \frac{d P_{a}\left(T_{c}\right)}{d t}
$$

\section{Micro pressure sensor}

We developed a micro pressure sensor to evaluate the thermal performance in the field where thermal conductivity cannot be measured [12]. The output value of the micro pressure sensor and the ambient pressure can be approximated by the following equation:

$$
A D_{\text {tot }}=A D_{a t m}+\frac{A D_{v a c}}{1+\frac{P a}{P_{1 / 2, a}}}
$$

To obtain the relationship between the output value of the sensor and pressure, an approximate value was obtained and compared with that from a known vacuum gauge (ULVAC, CCMT-D) (Fig. 1). All sensors used in the experiment were calibrated with this gauge, and the internal pressure was measured using these values.

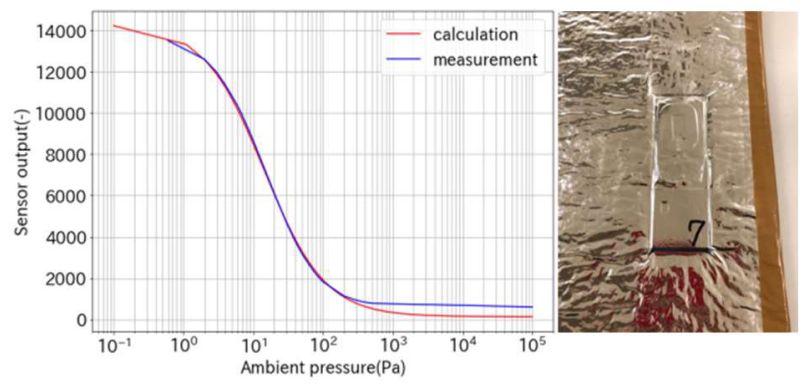

Fig. 1. Relation between sensor output and ambient pressure Fig. 2. Appearance of VIP with a pressure microsensor (right) 


\section{Getter}

Equation (4) shows that the long-term performance of VIP depends on internal pressure. Thus, it is known that it is effective to use a getter to keep the internal pressure low. An alloy getter has been widely used as a getter for glass fiber core VIPs due to its high adsorption performance; however, some materials are difficult to recycle. $[9,10]$ However, there are cases where inorganic or organic nanoporous materials (i.e., zeolite or activated carbon) are used as getters for VIP. The adsorption properties of these materials are mainly described by the Langmuir model (Eq. (13)) of monolayer adsorption. This model is used by assuming that there are no interactions between adjacent adsorbed molecules and that the adsorption energies are all uniform. If the adsorption energies are uniform at all sites, the pore size is generally uniform. However, it is difficult to put powder materials such as zeolites into VIP. Thus, it is thought that the use of granular zeolites hardened with a binder is easy to operate. Zeolite hardened by granulation has macropores that are formed between binders as well as micropores of the material. Therefore, we used granular zeolite shown in Fig. 3 for the experiment. The temperature dependence of the adsorption isotherm was evaluated using the multi-site Langmuir model [12-14] (Eq.(14)) that can represent multiple adsorption sites. We measured the $\mathrm{N}_{2}$ adsorption isotherms of the two zeolites using the constant volume method, Belosorp-Max (produced by MICROTRACK BELL). The materials used had an average pore diameter of less than $5 \AA$ and were granulated with an aluminum oxide binder with the weight ratio of $20-30 \%$.

$$
\begin{gathered}
n=\frac{A B P}{1+B P} \\
\mathrm{n}=\sum_{j=1}^{k} \frac{A_{i} B_{i} P}{1+B_{i} P} \\
A_{i}=a_{, i}+c_{i} / T, B_{i}=b_{i} \exp \left(\frac{E}{R T}\right)
\end{gathered}
$$

where $a_{i}$ and $b_{i}$ are the saturation capacity and affinity parameter on the $i^{\text {th }}$ site respectively. Tables 1,2 and Figs. 4, 5 show the measurement results and the approximate expressions of the adsorption isotherm of the two zeolites at 283 to $363 \mathrm{~K}$ and the respective parameters.

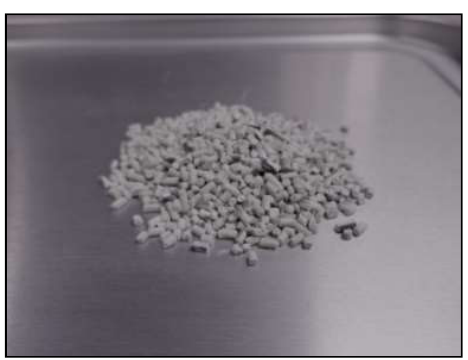

Fig. 3: Getter Appearance

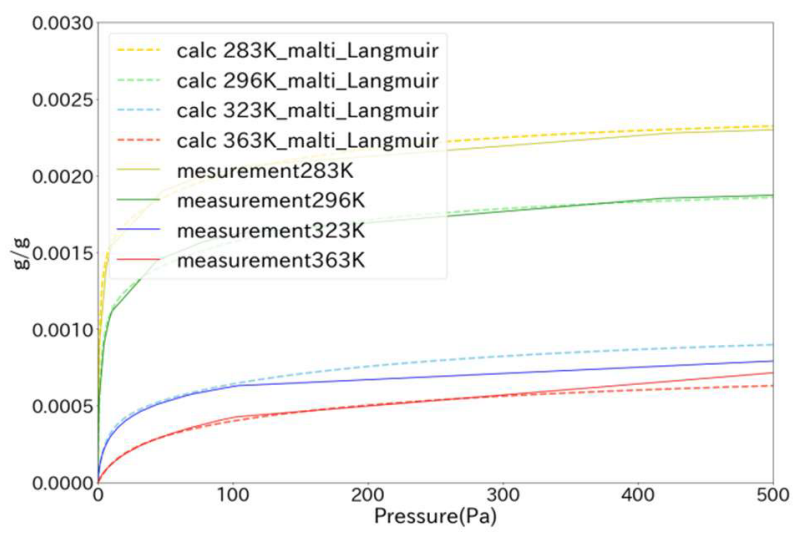

Fig. 4. Adsorption isotherm of getter1

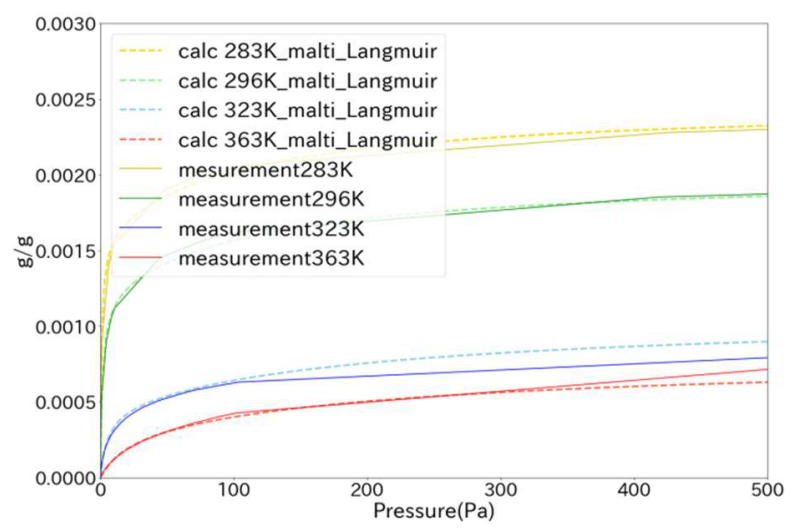

Fig. 5. Adsorption isotherm of getter2

Table 1. Fitting parameter of the adsorption isotherm (getter1)

\begin{tabular}{|c|c|c|c|c|c|c|}
\hline Temperature, $\mathbf{K}$ & $\boldsymbol{a}_{\mathbf{1}}$ & $\boldsymbol{a}_{\mathbf{2}}$ & $\boldsymbol{b}_{\mathbf{1}}$ & $\boldsymbol{b}_{\mathbf{2}}$ & $\boldsymbol{c}_{\mathbf{1}}$ & $\boldsymbol{c}_{\mathbf{2}}$ \\
\hline 283 & $2.6 \times 10^{-5}$ & 0.0105 & 0.093 & 0.000092 & 0.001 & 0.01 \\
\hline 296 & $1.4 \times 10^{-5}$ & 0.0088 & 0.02 & 0.000092 & 0.001 & 0.01 \\
\hline 323 & $7.5 \times 10^{-6}$ & 0.004 & 0.004 & 0.000092 & 0.001 & 0.01 \\
\hline 363 & $3.5 \times 10^{-6}$ & 0.0001 & 0.001 & 0.000092 & 0.001 & 0.01 \\
\hline $\begin{array}{c}\text { Relationship of } \\
\text { temperature }\end{array}$ & $\begin{array}{c}3.51 \times 10^{-9} \\
\exp (2489 / \mathrm{T})\end{array}$ & $13.73 \times(1 / \mathrm{T})-0.038$ & $\begin{array}{c}1.4 * 10^{-10} \\
\exp (5643 / \mathrm{T})\end{array}$ & - & - & - \\
\hline
\end{tabular}

Table 2. Fitting parameter of the adsorption isotherm (getter2)

\begin{tabular}{|c|c|c|c|c|c|c|}
\hline Temperature, $\mathbf{K}$ & $\boldsymbol{a}_{\mathbf{1}}$ & $\boldsymbol{a}_{\mathbf{2}}$ & $\boldsymbol{b}_{\mathbf{1}}$ & $\boldsymbol{b}_{\mathbf{2}}$ & $\boldsymbol{c}_{\mathbf{1}}$ & $\boldsymbol{c}_{\mathbf{2}}$ \\
\hline 283 & 0.0016 & 0.0008 & 1.2 & 0.0098 & 0.01 & 0.02 \\
\hline 296 & 0.0012 & 0.00071 & 0.7 & 0.009 & 0.01 & 0.028 \\
\hline 323 & 0.00046 & 0.0005 & 0.19 & 0.0047 & 0.01 & 0.04 \\
\hline 363 & 0.0003 & 0.00035 & 0.05 & 0.0042 & 0.01 & 0.055 \\
\hline $\begin{array}{c}\text { Relationship of } \\
\text { temperature }\end{array}$ & $\begin{array}{c}5.36 \times 10^{-7} \\
\exp (2256 / \mathrm{T})\end{array}$ & $\begin{array}{c}1.7 \times 10^{-5} \\
\exp (1087 / \mathrm{T})\end{array}$ & $\begin{array}{c}5.36 \times 10^{-7} \\
\exp (4148 / \mathrm{T})\end{array}$ & $\begin{array}{c}1.43 \times 10^{-4} \\
\exp (1197 / \mathrm{T})\end{array}$ & - & $-47.12 / \mathrm{T}+0.1779$ \\
\hline
\end{tabular}


The measured values of the adsorption isotherm agreed well with the calculated values obtained from the multi-Langmuir model, and the temperature dependence of each parameter was confirmed. Therefore, it is considered that these getters also have the temperature dependence of gas adsorption inside VIP. The long-term performance of VIP with getter was calculated by Equation 8 by taking into account the adsorption isotherm and comparing the calculated and measured values.

\section{Prediction of long-term performance under constant environment}

\subsection{Comparison of measured and micro pressure sensor values}

The output value of the pressure sensor was converted to pressure using Eq. (12), and the thermal conductivity was calculated from E. (4). The calculation results were compared with the actual insulation performance measured with a heat flow meter device conforming to Japanese Industrial Standards (JIS) 1412 Part II. Table 3 summarizes the material composition of VIP used for the measurement. As mentioned above, the micro pressure sensor was calibrated before making VIP. Fig. 6 shows the comparison of the result of long-term performance. For each getter, it was confirmed that the measured value by the heat flow meter method and the value calculated from the micro pressure sensor were almost the same. Using the calibrated sensors to calculate the internal pressure of VIP provided sufficient accuracy to estimate the thermal conductivity. Thus, this method can measure changes in thermal conductivity in the field where a heat flow meter device is not available. However, because the thermal conductivity value is based on the relational expression (4) between the pressure and the thermal conductivity measured by the heat flow meter method, the thermal performance may be lower in an environment with a larger temperature difference. Next, it is necessary to confirm the relationship between the thermal performance under different conditions to more accurately determine the change on site.

\subsection{Comparison between measured and calculated thermal conductivity by considering the adsorption isotherm of the getter}

To verify the validity of Equation 8, the internal pressure change was calculated using the adsorption isotherm of the getter material and compared with the measured value. Calculations were made under the same conditions as those used for VIP shown in Table 3 and compared with the actual measurements shown in Fig.7. Both the calculated values of getter 1 and getter 2 were close to the measured values. However, in VIP with getter2, the actual measured value slightly changed during the performance; however, the calculated value did not change. This result was obtained because only $\mathrm{N}_{2}$ was used for the adsorption isotherm. Gas permeation into VIP includes not only $\mathrm{N}_{2}$ but also $\mathrm{O}_{2}$ and Ar.
Specifically, Ar, which does not adsorb well to the getter, is assumed to cause a gradual increase in the internal pressure. Therefore, we want to improve the accuracy of long-term performance prediction by measuring the adsorption isotherm of other gases and investigating what gases remain inside VIP without being adsorbed.

Table 3. Details of VIP with the micro pressure sensor

\begin{tabular}{|c|c|}
\hline VIPs Size & $\mathrm{t} 15 \times 390 \times 670$ \\
\hline Core & Glass fiber \\
\hline Film & Hybrid Type \\
\hline Desiccant & Calcium oxide, $20 \mathrm{~g}$ \\
\hline Getter & No1/getter $1,5 \mathrm{~g}$ \\
No2/getter $2,5 \mathrm{~g}$
\end{tabular}

※1: HC-076 600 (EKO Instruments, Japan)

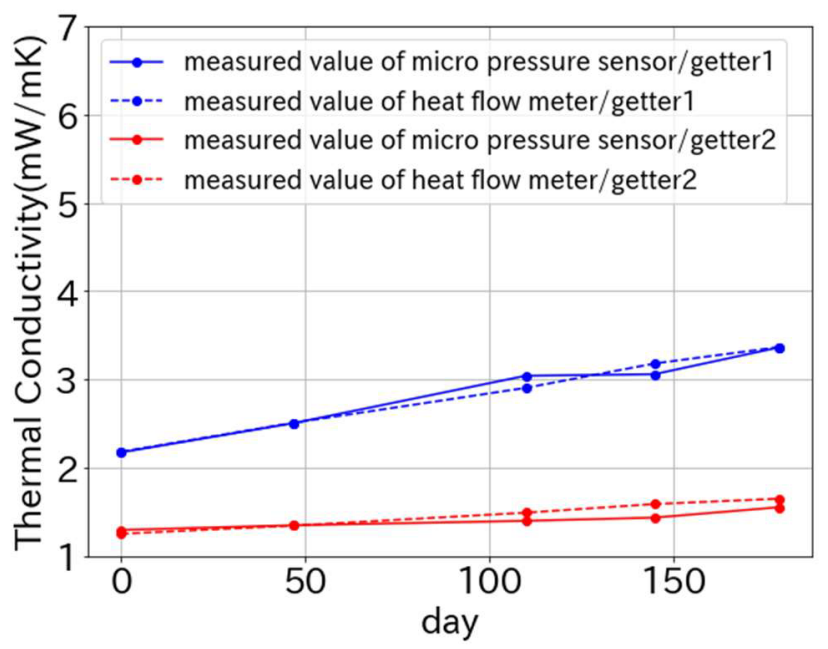

Fig. 6. Comparison of sensor output and measured values of thermal conductivity

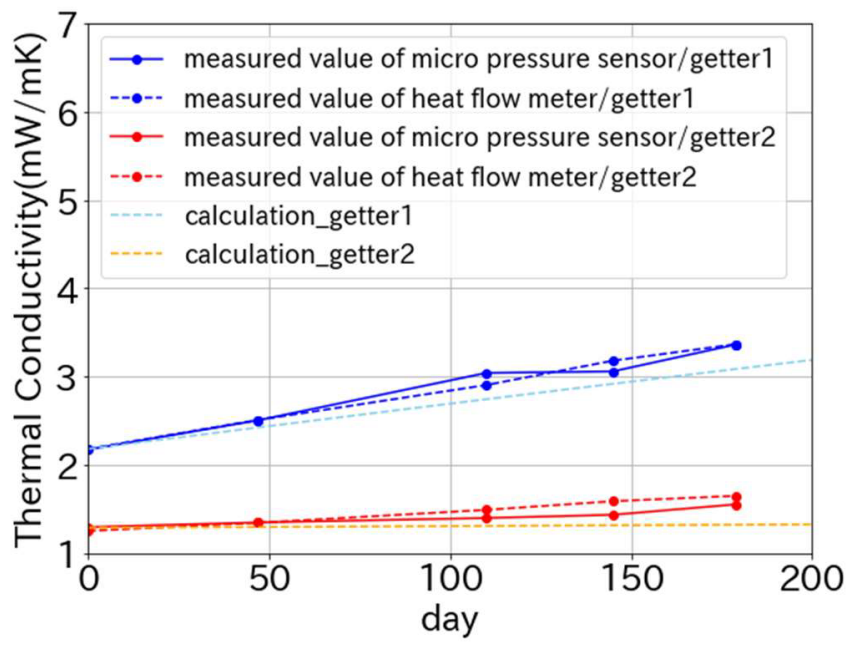

Fig. 7. Comparison of sensor output and measured values of thermal conductivity and those calculated by Eq. 8 


\section{Measurement of long-term performance on site}

The long-term performance of VIP installed inside the outer wall of a factory was measured using a micro vacuum sensor [15]. This building is located at an altitude of $158 \mathrm{~m}$. The surrounding climate is classified as Japan's humid subtropical climate. VIP was constructed on the inner side of the outer wall of the area hatched in red (Fig. 8). The installation area of VIP is approximately $81 \%$ on the south side of the area of the outer wall (Fig. 9). Because there are no windows, there are almost no thermal bridges except for steel frames. A urethane spray with an approximately $15 \mathrm{~mm}$ thickness was applied to the surface of VIP. Furthermore, the thermal bridge of the steel frame was also thermally insulated by the urethane spray. The composition of the thermal insulation materials is shown in Table 4 and Fig. 10. VIPs with an inserted micro pressure sensor were installed at a height of $1.5 \mathrm{~m}$ from the ground on the south and southeast side and at a height of approximately $10 \mathrm{~m}$ from the ground on the southeast side, respectively. The environmental conditions required to predict the long-term performance of VIP using the same materials as those shown in Table 3 at $1.5 \mathrm{~m}$ were measured using temperature and humidity sensors (SHT35, Sensirion) (Fig. 11). The average temperature difference between the front and back of VIP during the measurement period was $0.1^{\circ} \mathrm{C}$, and the average temperature inside the room was $20.5^{\circ} \mathrm{C}$. Therefore, we calculated the long-term performance of VIP exposed to the constant environment of $20.5^{\circ} \mathrm{C}$ with Eq. 8 and compared it with the measured value by the micro pressure sensor. Fig. 12 shows the result of calculating the change over time of the thermal conductivity from the output value of the pressure sensor inserted into the VIP installed at the site. This VIP uses the same materials as those shown in Table 3 , and the VIP size is $12 \times 450 \times 870$.

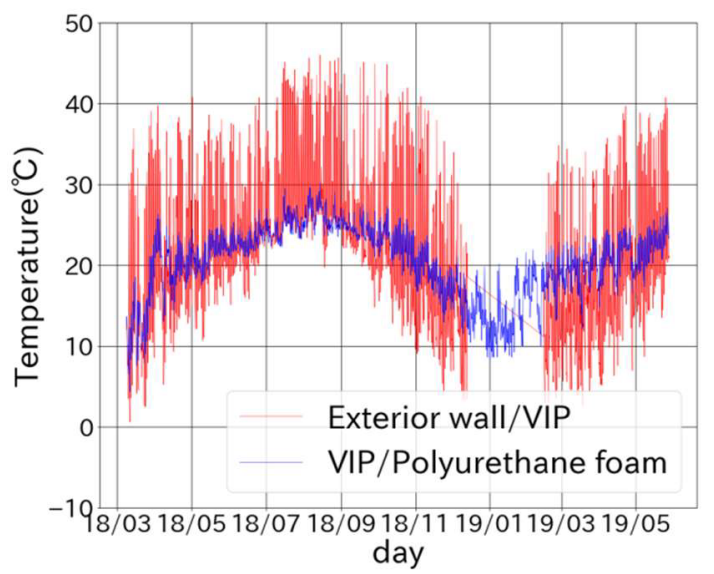

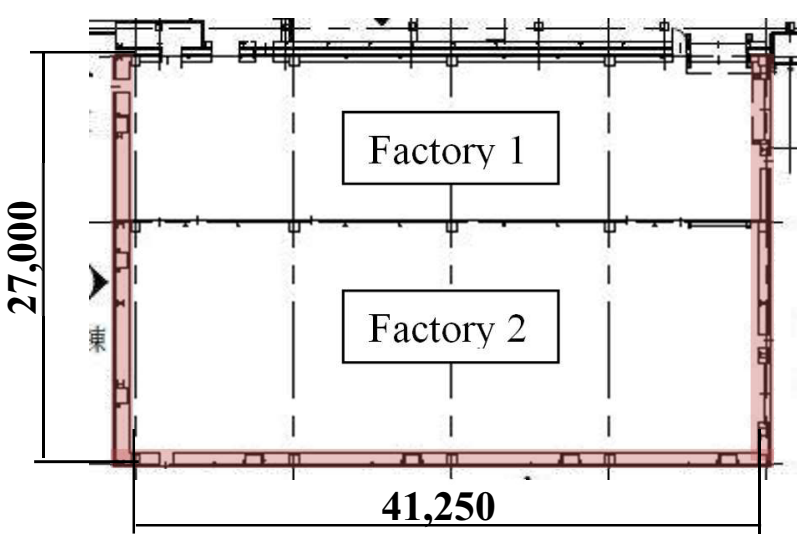

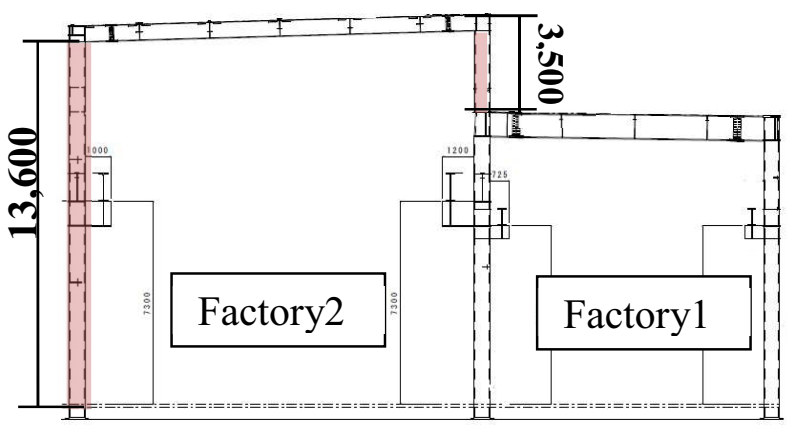

Fig. 8. Plan view and north-south sectional view
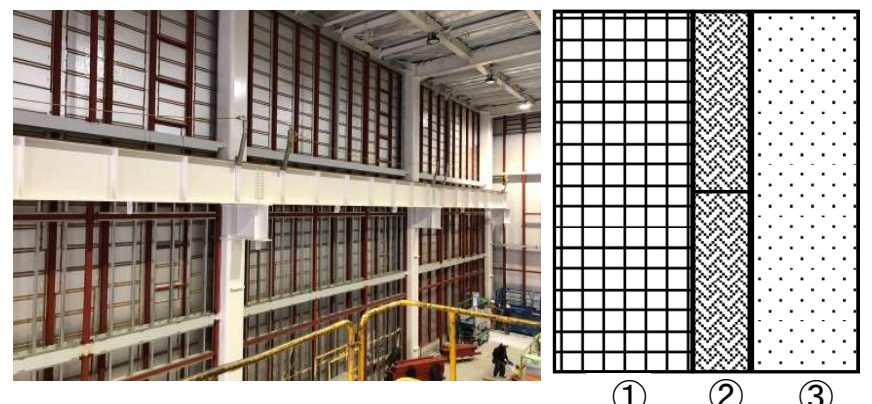

Fig. 9. Appearance after VIP construction (south side), left

Fig. 10. Wall cross-section, right, (components are explained in Table 4)

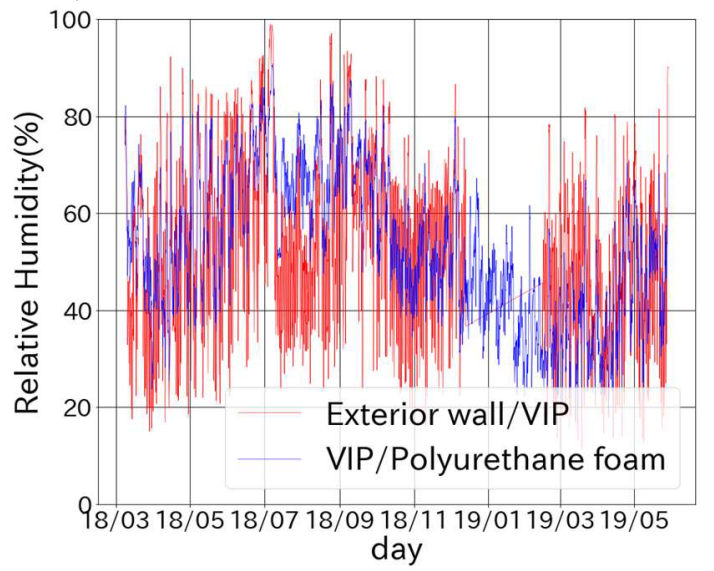

Fig. 11. Temperature (left) and relative humidity (right) measurement results at the front and back of VIP on the south side wall

Table 4. Thermal properties of the insulation used at this factory

\begin{tabular}{|c|c|c|c|c|}
\hline No & Insulation & Thermal Conductivity $(\mathrm{mW} / \mathrm{mK})$ & Thickness (mm) & $R$ value $\left(\mathrm{m}^{2} \mathrm{~K} / \mathrm{W}\right)$ \\
\hline (1) & Exterior wall & 20 & 30 & 1.75 \\
\hline (2) & VIPs & $2.5 \geqq^{* 1}$ & 6 & $2.4 \leqq^{* 1}$ \\
\hline (3) & Spray urethane & 38 & 15 & 0.39 \\
\hline
\end{tabular}




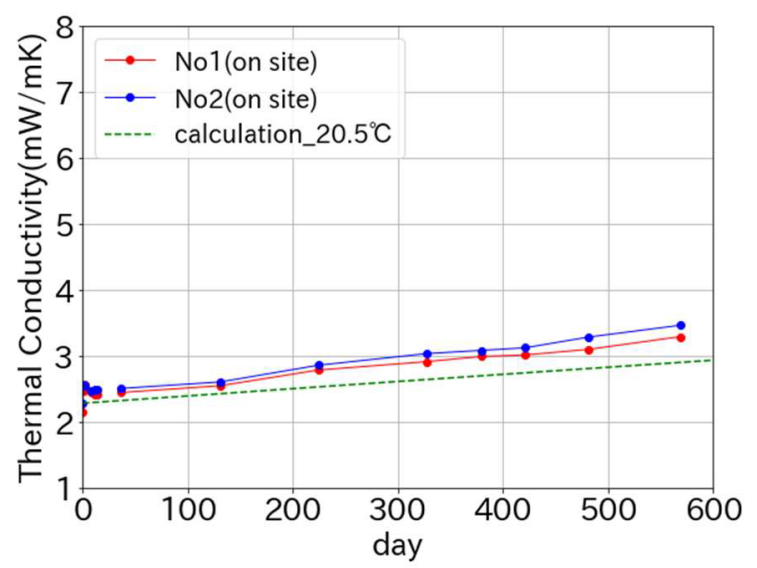

Fig. 12. Long-term performance of VIP on site measured by the micro pressure sensor

Considering the average temperature during the entire measurement period, the inside and outside of the factory had similar temperatures; thus, it was assumed that there was no large difference between the measured and calculated values. However, because this calculation does not correctly take environmental conditions into account, we plan to calculate the long-term performance for the entire period under the temperature and humidity conditions shown in Fig. 11 to perform a more accurate calculation.

\section{Conclusion}

The adsorption isotherms of two types of materials based on zeolite, getter1 and getter2 were measured for VIP getter materials. Getter1 had poor adsorption power in the low pressure region, and getter2 showed high adsorption power in the low pressure region. The adsorption isotherm of the getter material exhibits temperature dependence and can be represented by the existing adsorption model (multi-Langmuir model). When comparing the two types of getters, getter 2 has a lower pressure increase and exhibits stable performance for a long time. This depends on the difference in the amount of adsorption at low pressure of the adsorption isotherm of the getter. Furthermore, by evaluating the adsorption isotherm using the mass balance equation, the internal pressure change of VIP considering gas adsorption can be calculated, and we calculated from the nitrogen adsorption isotherm; however, the measured and calculated values were slightly different. This is attributed to the following two effects:

- Effect of gas that does not cause adsorption,

- Adsorption behavior of gases other than nitrogen.

Next, the measured value of the thermal conductivity of the VIP including the micro pressure sensor was compared with the calculated value from the output value of the sensor, and it was confirmed that the calculated values agreed well with measured values. Since thermal conductivity cannot be measured in a building environment, this measurement method is considered to be effective in measuring the long-term performance of VIP in a building environment. Using this method, we measured the internal pressure of the
VIP installed in the building environment and compared it with the calculated value considering a permeation of gases and an adsorption to getter. The calculated value was lower than the measured value. The main factor is that the type of gas that cannot be adsorbed is not taken into account and the average temperature is used, and we will work on improving it soon.

\section{Symbols}

$\lambda_{\text {cop }}$ : thermal conductivity at the center of the panel $[\mathrm{W} / \mathrm{mK}] ; \lambda_{\text {cop,ini }}$ : initial thermal conductivity $[\mathrm{W} / \mathrm{mK}] ; \lambda_{g}$ : gaseous thermal conductivity $[\mathrm{W} / \mathrm{mK}] ; M_{i}$ : Avogadro's constant $[\mathrm{kg} / \mathrm{mol}] ; V_{\text {eff }}$ : volume of VIP $\left[\mathrm{m}^{3}\right]$; $R$ : gas constant $[\mathrm{J} / \mathrm{Kmol}] ; P_{i, a t m}$ : partial pressure of gas under atmospheric pressure $[\mathrm{Pa}] ; P_{i}$ : pressure inside VIP $[\mathrm{Pa}] ; K_{i, t o t a l}$ : overall transmittance $(I=a, v)\left[\mathrm{g} / \mathrm{day} \cdot \mathrm{Pa} \cdot \mathrm{m}^{2}\right] ; A D_{\text {tot }}$ :sensor output $[-] ; A D_{\text {vac }}$ : sensor output under vacuum $[-] ; A D_{a t m}$ : sensor output at atmospheric pressure $[-] ; W_{a d}:$ mass of gas adsorption $[\mathrm{g} / \mathrm{g}]$

\section{References}

1. M.G. Kaganer. Thermal insulation in cryogenic engineering (1969)

2. S. Brunner, H. Simmler. In situ performance assessment of vacuum insulation panels in a flat roof construction (2007)

3. P. Mukhopadhyaya, D. Maclean, J. Korn, D. van Reenen, S. Molleti. Building application and thermal performance of vacuum insulation panels (VIPs) in Canadian subarctic climate (2017)

4. P. Johansson, B. Adl-Zarrabi, A. S. Kalagasidis, Evaluation of 5 years' performance of VIPs in a retrofitted building acade (2015)

5. D. Maclean, P. Mukhopadhyaya, J. Korn, S.Mooney. Design details and long-term performance of VIPs in Canada's North (2016)

6. H. Simmler, S. Brunner. Vacuum insulation panels for building application Basic properties, aging mechanism and service life (2005)

7. E.Wegger, B. Petter.Jelle, E. Seipe, S. Grynning, A. Gustavsen, R. baetens, J. V. Thue. Aging effects on thermal properties and service life of vacuum insulation panels (2011)

8. E. Pons, B. Yrieix, S. Brunner. Evaluation of VIPs After mild artificial aging during 10 years: Focus on the core behaviour (2017)

9. J.S. Kwon, C. H. Jang, H. Jung, T.H. Song. Vacuum maintenance in vacuum insulation panels exemplified with a staggered beam VIP (2009)

10. X. Di, Y. Gao, C. Bao, S. Ma. Thermal insulation property and service life of vacuum insulation panels with glass fiber chopped strand as core materials (2013)

11. D. Ogura, A. Iwamae, T, Tasaka, K. Mabuchi Y. Senda, K. Kugimiya. Prediction on long-term performance of vacuum insulation panels(VIP) using glass fiber core considering differences in hydrothermal environment and size of VIP and influence desiccant, 14th International Vacuum Insulation Symposium (2017) 
12. T Nitta, T Shigetomi, M.Kuro-oka, T.Katayama. An adsorption isotherm of multi-site occupancy model for homogeneous surface (1984)

13. Jose A. C. Silva and Alirio E. Rodrigues. Multisite Langmuir Model Applied to the Interpretation of Sorption of n-Paraffins in 5A Zeolite (1999)

14. Karen N.Son, Gregory E. Cmarik, James C.Knox, Justin A. Weibel, Suresh V. Garimella Measurement and Prediction of the Heat of Adsorption and Equilibrium Concentration of $\mathrm{CO} 2$ on Zeolite $13 \mathrm{X}$ (2018)

15. H. Yamamoto, D, Ogura. Utilization of the vacuum insulation panels in a factory and comparison of long term performance measurement using micro-pressure sensor and prediction value, 15th International Vacuum Insulation Symposium 2019 (2019) 